\title{
Reconciling Process and Outcome in Evaluating Community Initiatives
}

MIKE HUGHES

Principal Officer, Research and Development, Barnardo's

\section{TISH TRAYNOR}

Evaluation Manager, Barnardo's Anti-Poverty Strategy

Community development initiatives need to be evaluated as rigorously as any other social intervention. Perceived impediments include:

- a necessary focus on process;

- problems of attribution;

- the time-scale necessary to bring about community change;

- finding useful data whereby to appraise outcome.

A 'Theory of Change' approach overcomes many of these obstacles; it involves making sure that you know what you want to achieve, when you want to achieve it by and that you know how you are going to get there, adapting methods and goals as you go along.

The evaluator plays an active role in working out, with all stakeholders, the long-term objectives for the initiative. The mid-term objectives are then defined, and a theory of change specified. Next, the early stage objectives are defined, and the Theory of Change is suggested, linking this to the midpoint objectives. It is possible to judge at any point in the process of the intervention the achievement of the stated objectives so far and the probability of arriving at a useful outcome.

An example of a complex community intervention being applied in eight areas of the UK is described, illustrating the 'theory of change' approach, and some preliminary results are reported.

The myth that community development initiatives are only partially susceptible to evaluation needs to be challenged, since there rests on the community development practitioner and manager as much obligation to consider effectiveness as there is with any other social intervention. It is suggested frequently by community development practitioners that their work cannot be evaluated fully, not least because they believe that evaluators do not fully understand the process of community development. They may be right, but such an assertion does not 


\section{Evaluation 6(1)}

diminish the need to know whether community development works. The four principal issues which tend to be raised are all in some sense linked to the structural complexity of any community.

The first issue is timescale: how long does it take to bring about social change in a community? Policy makers, planners and funders would like it to take a relatively short period of time - one, two or three years. To commit funding and direction for longer than this would require a major expression of trust that the intervention would succeed, without any interim assurances. From the other point of view, a community which has been in a disadvantaged state for many decades, if not generations, will require much preliminary work in order to perceive itself as able, well resourced and ready to mobilize towards change. In the middle ground, an element of mistrust has arisen. Community development professionals believe that the process of regeneration needs many years' work, and that policy makers and policy evaluators under-represent this; in their turn, the latter may wonder whether such an assertion is in part due to a reluctance to examine rigorously the effectiveness of community interventions.

The second issue concerns how you can clearly attribute change or growth to the social intervention? Such evaluative techniques as have been developed in this field cannot absolutely exclude other causality. Rossi and Freeman (1989) offer an elegant typology of 'confounding factors':

- endogenous change - the natural sequence of events;

- secular drift - long-term trends;

- interference - short-term events;

- maturational trends - natural demographic change;

- uncontrolled selection - non-random choice, e.g. of local subjects, for evaluation.

Even if the intervention is highly effective within itself, it is operating within the structure of the community, which in turn operates within a wider (and, increasingly, global) context.

Third, how will a credible data-set be assembled whereby to appraise outcomes? Will this be acceptable to all interested parties? How will we arrive at an image of what success will look like? The same tension or mistrust may emerge at this stage, when community members, community development staff and strategic planners each have a different concept of what constitutes success, and of what its indicators will be.

Each of these factors links in some sense to the fourth impediment, namely that in community development there is a necessary focus on the process of intervention, sometimes seen as an end product in its own right. The relationship between the two occupies an extensive place in community development evaluation literature. Gaffikin and Morrissey (1994), in their evaluation of the Brownlow Community Trust (part of the Third European Poverty Programme), stopped short of saying definitively that the intervention has changed the lives of the people. They list the social structures and activities now present and suggest obliquely that such processes are likely to contribute to the well-being of the community: 


\section{Hughes \& Traynor: Reconciling Process and Outcome}

In addressing the intricate questions of additionality and dead-weight in the project, several broad conclusions can be drawn - in terms of outputs, amongst the initiatives which are both exclusively attributable to the interventions of BCT and are likely to prove durable beyond its lifespan, are the following:

- The establishment of a Women's Centre, and around it an array of activity on family support.

- The health centre users' group, and the health promotion work.

- The provision of crèche facilities, and the catalysing of the Council's development policy on child play.

- The raising of awareness and co-ordination of a set of policies for young people, involving in particular the Youth Service and Health and Social Services.

- A positive transformation of the culture of agencies.

- A range of community education and training activity.

(Gaffikin and Morrissey, 1994: 85-6)

They refer to the core tension between achievement of results, such as the removal of poverty, and the setting up of structures and processes:

The duration of Poverty 3 is insufficient to allow such questions to be fully answered. Indeed, they relate to the capacity of the project to intervene and offset, possibly reverse, the dynamics of poverty generation in the area. As such, the optimum impact of the project is more about putting structures in place and initiating processes than achieving a measurable reduction in poverty. (Gaffikin and Morrissey, 1994: 39)

Sadan and Churchman (1997) suggest that process and outcome (or product) tend to become polarized, and that excessive emphasis on product is disempowering to a community. They draw from the literature six dimensions of the planning process:

1. directive or non-directive intervention;

2. service delivery-focused or resident-focused work;

3. centralized or de-centralized decision making;

4. focused or open-ended task definition;

5. community as object or community as subject;

6. expert or reflective practitioner.

They suggest that for the purpose of empowering a community, the planning process should be non-directive, resident-focused, de-centralized, open-ended, community-as-subject and reflective. Leaving aside the question of the validity of the concept of empowerment itself (a much argued issue - cf. Christian, 1998), it would appear that the two perspectives represented respectively by 'process' and 'outcome' need to be reconciled if a planning and evaluation system is to be developed which reflects all reasonable interests. By way of re-framing the four original problems or issues, we need to consider the following four questions:

i. How do you distinguish between generating significant community activity and producing significant results?

ii. If improvements are achieved, how can you be sure what has accomplished them? 


\section{Evaluation 6(1)}

iii. Since major community change necessarily takes many years, how can you have confidence in the early years that you are on the right course?

iv. What data will accurately tell you that you have achieved positive outcomes?

The response to these questions could be framed in one of two ways. First, what data should be collected in order to respond to the core research questions of an intervention and how and when should it be gathered? There have been a number of different responses to this question, most important of which is the work of Barr et al. (1996).

Second, and this forms the focus for the remainder of this article, what overall approach should be taken in order to ensure that due weight be given to the key factors, process and outcome? It is suggested that a Theory of Change approach achieves just that, and it has the dual advantage of being rigorous and simple. It is not a new approach - it has recently re-emerged in relation to community development (Connell and Kubisch, 1996) but has a longer history in the evaluation of social interventions (for example, Chen, 1990; Chen and Rossi, 1992).

Weiss (1995) explores the difficulties raised in evaluating 'comprehensive community initiatives' and she suggests the idea of basing evaluation on the theory or theories of change which underlie the initiatives:

The concept of grounding evaluation in theories of change takes for granted that social programmes are based on explicit or implicit theories about how or why the programme will work. (p. 66)

Weiss examines the assumptions which underpin any social intervention. For example, in a job training programme for disadvantaged young people, where the goal is to get the disadvantaged young people into the work force, she lists 15 assumptions, each of which comprise a step in the theory whereby change will be achieved. They include the accessibility of training, information reaching the target audience, attendance being regular, good quality training being provided, availability of jobs on conclusion of training and the supportive backing of employers.

She goes on to argue that there are four good reasons why evaluation should be theory-based: (i) it focuses the evaluation on the key aspects of the programme; (ii) it enables the results from the evaluation to be fed into the wider knowledge of such programmes; (iii) it requires the operational staff to be explicit about their assumptions; (iv) and is therefore likely to be more influential in addressing the policy and opinion.

The concepts outlined by Weiss were formulated into a paradigm of evaluation by Connell and Kubisch (1996). They describe Theory of Change as a story of how and why an initiative works. It is based on a few straightforward principles: make sure that you know what you want to achieve, and by when; make sure that you know how you are going to get there; be prepared to adapt your methods and goals as you go along.

There are three stages in any Theory of Change evaluation.

First, the evaluator, jointly with the community members, development staff and other partners, defines what they require the long-term outcomes to be. They 
Hughes \& Traynor: Reconciling Process and Outcome

\begin{tabular}{|c|c|c|c|c|c|c|c|c|}
\hline $\begin{array}{l}\text { Step 5: } \\
\text { Initial } \\
\text { Activities }\end{array}$ & $\rightarrow$ & $\begin{array}{l}\text { Step 4: } \\
\text { Early } \\
\text { Outcomes }\end{array}$ & $\rightarrow$ & $\begin{array}{l}\text { Step 3: } \\
\text { Intermediate } \\
\text { Outcomes }\end{array}$ & $\rightarrow$ & $\begin{array}{l}\text { Step 2: } \\
\text { Penultimate } \\
\text { Outcomes }\end{array}$ & & $\begin{array}{l}\text { Step 1: } \\
\text { Long-term } \\
\text { Outcomes }\end{array}$ \\
\hline
\end{tabular}

Figure 1

then work backwards from that endpoint to the steps required to get there, as shown in Figure 1.

It will be evident from the example given later in this article that early stage objectives are very much characterized by a flavour of process. Longer-term objectives, the first to be defined, need to be expressed both as outcomes and as process. So, there will be a transition away from process only to a greater inclusion of outcome focus, as the initiative proceeds. At agreed points within the intervention, the evaluator will meet with the other parties in order to take stock of achievement and revise the remainder of the programme in the light of this experience. Early stage objectives will be defined most explicitly, while long-term objectives may be more grand and aspirational. As one draws nearer to the point of delivery of an objective, it is made sharper and more focused. So, it is possible to make an appraisal at any point in the process of intervention about the achievement of the stated objectives so far, and about the probability of arriving at a people-centred end product. This is all that a planner or funding agency can expect - it ought to provide the assurance that the intervention is on course and therefore worthy of funding.

In the view of Connell and Kubisch, a good Theory of Change contains four elements:

1. It will be plausible - common sense will tell you that it can be done.

2. It will be testable - explicit enough in its stages to lend itself to observation.

3. It will be doable - the resources will be there to carry it out.

4. Results responsive - it will amend its end goal in light of experience.

Next, the theory will be tested by the collection of data that corresponds to the process and outcome objectives. Finally, an analysis will be conducted of this data, in order to see how far the practical experience corresponds with the aspirations set out in the original plan. In turn, the plan is modified for the remainder of the intervention so that the theory remains plausible, testable, doable and results responsive.

Barnardo's, a UK non-governmental organization focusing on the needs of children and young people, developed an Anti-Poverty Strategy (Doble and Hughes, 1994) designed to address child poverty within disadvantaged neighbourhoods in a fundamental way, through the medium of community development. They drew the model of intervention principally from the Third European poverty programme (or Poverty 3 , already referred to in the evaluation of the Northern Ireland initiative reported by Gaffikin and Morrissey, 1994). The principles which informed the strategy were the same as those of Poverty 3: 


\section{Evaluation 6(1)}

- Participation of people living in poverty in neighbourhoods is an absolute essential from the beginning - there must be a formal structure which enables this participation from the outset, for example, local people working on the project, local people on the board of management of the project.

- The partnership principle - groups of agencies who are funding the developments, and who exercise some collaborative power and control over the overall approach.

- Any serious attempt to minimize the effects of poverty must be multidimensional. It must address all known negative features, or the remainder will have a downward effect on the rest.

- Additionally, because of the nature of Barnardo's a fourth principle was added, namely that the intervention would be child-focused.

Eight distinct local community partnerships would be developed, intended to address every aspect of the disadvantage within a neighbourhood, focusing particularly on the needs of the child or young person. Transforming this into a series of research questions produced the following:

- Is it possible to make a significant and lasting difference to the lives of children in a disadvantaged community by linking community members and relevant partner organizations to address all aspects of the perceived disadvantage?

- What features of such a venture would contribute to its success or failure?

- What is the distinctive contribution of the voluntary sector to the initiative?

- What can a children's organization such as Barnardo's contribute?

In order to address the questions, two research staff were appointed, who were to engage with the local initiatives and take them through the four following stages of the evaluation process:

1. designing a profile of the community, a baseline from which change could be gauged;

2. constructing goals for the intervention jointly;

3. observing the process of intervention;

4. appraising the outcome.

Having in mind the approach suggested by Connell and Kubisch, several quite ambitious goals have been set by each initiative or partnership. Typically they consist of some of the following, although it needs to be stressed that this list is not that of any one initiative, rather illustrative of the overall approach:

- increased participation in housing lettings policy and housing management;

- less exploitative economic activity (for example, in relation to loans for home-based work);

- a more flourishing internal economy;

- an improvement in employment within the neighbourhood;

- the presence of community-based skill-training resources;

- locally-owned and managed trading opportunities; 
- increased leisure opportunities in the neighbourhood for all age groups;

- some improvement in levels of health of young children;

- greater facilities for play, child care and early years education.

It is worth restating the Theory of Change which underpins this initiative and is implicit in the research questions, namely that through applying principles of participation, partnership, multi-dimensionality and child-focus, outcomes such as those just listed will be achieved. It is salutary at this stage to consider the hypothesis in terms of the assumptions issue raised by Weiss. In relation to community initiatives, she suggests that the assumptions implicit in such an intervention would be:

- you can make an impact with limited funds;

- an effective programme requires the involvement of local citizens;

- urban neighbourhoods are appropriate units on which to focus programme attention;

- neighbourhood action will achieve the initiative's goals;

- comprehensive services will lead to success;

- social service interventions will succeed irrespective of employment conditions;

- services for adults confer benefits on children.

If we then apply a Theory of Change approach to the intended outcomes, we would arrive at the five-year plan set out in Table 1 (the Barnardo's initiative is at least originally funded for five years).

This is not an immovable blueprint, rather an instrument to be used flexibly in the planning and evaluation processes. Since adaptability in the light of experience (results responsiveness) is one of the features, it is a relatively affirming approach - it does not set out to encourage failure, rather to ensure flexible planning.

In the course of the five years of the intervention, periodic reports are being produced which reflect the planning process of the intervention itself. The evaluation has therefore also adopted a Theory of Change approach and it will be able to chart the extent to which the hypothesis is validated throughout the intervention.

The first evaluation report has been published (Traynor et al., 1998), and some tentative lessons can already be drawn out.

Each of the pilots has now become well established, has strong links with its community and with local partners, and is already delivering a combination of process outcomes (establishing groups and networks, etc.) and actual outcomes which are of value to people, especially to children. In relation to the four key principles of the intervention, the following should be noted:

\section{Partnership}

i. There is a risk that tension may form between the voluntary agencies involved in a local initiative - some have a national focus, some local, and some have a broader focus than the target group that any one smaller 
Evaluation 6(1)

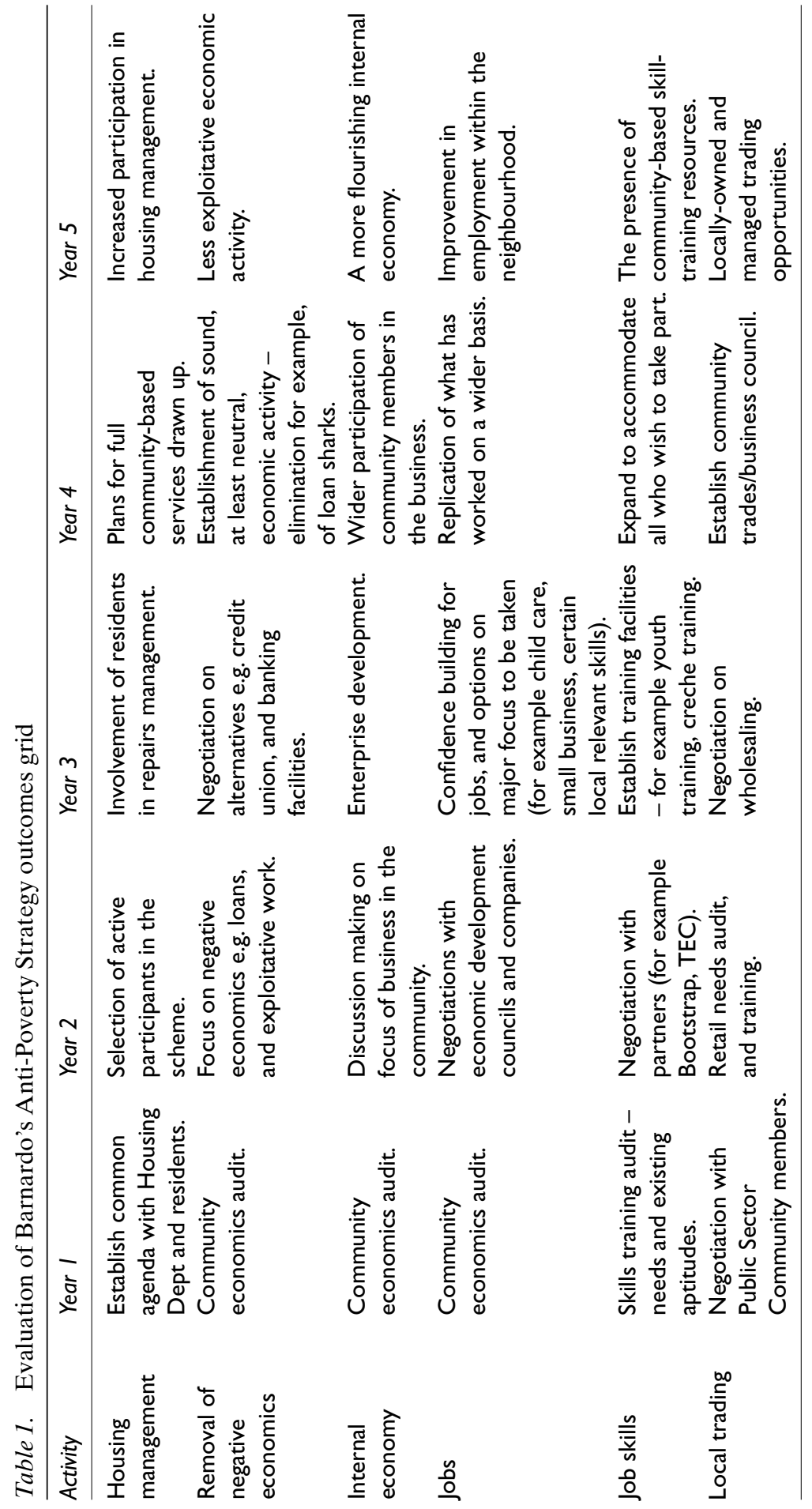


Hughes \& Traynor: Reconciling Process and Outcome

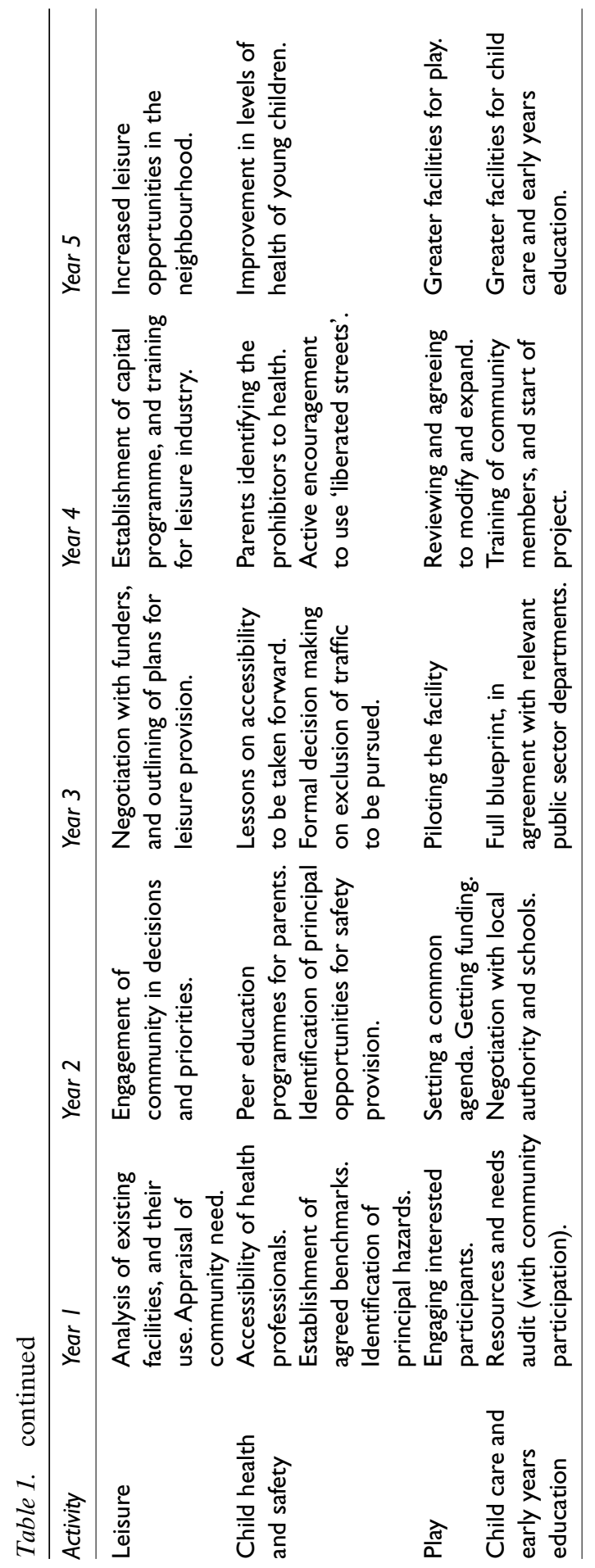




\section{Evaluation 6(1)}

group may be interested in. However, on the whole such tensions have been worked with and at least in part resolved.

ii. Once the pilots have become operational, partnership relationships tend to increase, most of all at operational level - at this point, there are around 100 partners involved with the pilots at a formal or informal level.

iii. The use of Barnardo's as a credible organization in relation to the statutory sector has meant a drawing together of strong working relationships between the public, voluntary and community sectors.

\section{Participation}

i. At an operational level, participation (community involvement) is the principle by which all community development takes place and therefore the most significant contributor to success.

ii. Many strong links have been achieved within local communities, and this is especially salutary when several of the communities did not themselves invite Barnardo's to engage.

iii. Engaging with the community was helped by the existence of other voluntary sector work in the area, either by Barnardo's or by other voluntary agencies.

iv. A focused activity such as child's play is likely to speed up the process of community involvement. The participants have to feel that they are getting something for themselves or their children before they may feel part of a community, since they themselves may feel isolated within an isolated community.

\section{Multi-dimensionality}

i. At this stage, the range of activities and factors of disadvantage addressed by the pilots has been small, and to this extent relatively few specified achievements are recorded in relation to multi-dimensionality. From the experience so far, it is safe to say that to address issues of poverty in a truly multi-dimensional way a staged process of development is required, a sound basis of positive collaboration is needed and a prioritizing of needs has to be made.

ii. Identifying a key interest and need, such as play or sport, has been the way in which a range of factors has got on to the agenda of communities; first identify an initial interest-rouser, then other things will cluster around it, ultimately working towards multi-dimensionality.

\section{Child focused}

i. Barnardo's association with children's work has been a key factor in the level of acceptability of involvement by people in the local communities.

ii. Whatever the level of disadvantage experienced or perceived within a community, there is a tendency by local people to see the lack of facilities and activities for children and young people as the most pressing need to be addressed. 
iii. The child focus of the work helps the identification and selection of relevant partnerships, and the level of involvement between the pilot staff and partner agencies.

iv. All of the pilots now involve direct work with children, and at an operational level many of them actually consult the children in the development of the ongoing activities which relate to them.

v. The child focus is also achieved through the other key factors - partnership, participation and multi-dimensionality - and equally, the child focus has wider benefits for the whole community.

Some tentative answers can be made to the original four research questions which underpin the whole evaluation:

1. Is it possible to make a significant and lasting difference to the lives of children in a disadvantaged community by linking community members and relevant organizations to address all aspects of perceived disadvantage?

Early indications from the outcomes and achievements suggest a strong validation of the components of partnership and participation as being instrumental in effecting a positive impact on the lives of children. Whether these positive impacts already achieved are 'significant and lasting differences' requires longerterm evaluation and assessment. What is evident so far within the pilots is that the process of forming and maintaining partnerships with agencies to create a forum for positive collaboration takes time and is not without difficulties.

2. What features of such a venture would contribute to its success or failure?

Evidence from the experience of the pilots would affirm that agency and group partnerships combined with the participation of local people are key contributors to the process of achieving results in the process and the outcomes.

3. What is the distinct contribution of the voluntary sector to the initiative? The main characteristic of a distinct contribution from the voluntary sector is the degree to which greater flexibility can be exercised in all of the activities. Initially the voluntary sector can make decisions on where they will be involved, why they will be involved in that area and with whom they may choose to work. There is a greater opportunity to be creative and more open to working with a community and respond to their stated needs without having the priority of meeting statutory requirements. Philosophically the voluntary sector is seen as good and wanting to help people rather than to control them - as a result, they are frequently more acceptable to the community than statutory bodies. There is still a need, however, to negotiate appropriate entry into a community and emphasize the intention to work with local people and not to reinforce any perceived disadvantage or to cause any devaluing or disempowering.

4. What can a children's organization such as Barnardo's contribute?

Within the experience of this Anti-Poverty Strategy, apart from being the initiating agency and contributing the majority of the funding, Barnardo's involvement so far has also resulted in several significant additions to the achievements. In the main, Barnardo's name, reputation for quality work and credibility as a child-care organization has enabled acceptance of involvement by the voluntary 


\section{Evaluation 6(1)}

and the statutory bodies and in the local communities. With partner agencies, Barnardo's has been a significant and strong link between the voluntary and the statutory bodies, and in many instances a coordinating point for local voluntary networks and groups.

\section{Summary}

The reconciliation of process and outcome in evaluating complex community initiatives can be in part carried out by the introduction of a rigorous articulation of the theory of change implicit in the intervention. The approach developed by the US Round Table on Comprehensive Community Initiatives for Children and Families is being applied to a series of eight local programmes managed by a UK children's charity. This approach enables accurate and reassuring reporting on the timely achievement of results appropriate to stage and context.

\section{References}

Barr, A., S. Hashagen and R. Purcell (1996) Monitoring and Evaluation of Community Development in Northern Ireland. Belfast: Northern Ireland Office, Voluntary Activity Development Branch.

Chen, H. (1990) Theory-Driven Evaluations. Newbury Park, CA: Sage Publications.

Chen, H. and Peter H. Rossi (eds) (1992) Using Theory to Improve Program and Policy Evaluations. New York: Greenwood Press.

Christian, M. (1998) 'Empowerment and Black Communities in the UK: with Special Reference to Liverpool', Community Development Journal 33(1): 18-31.

Connell, J. P. and A. C. Kubisch (1996) Applying a Theories of Change Approach to the Evaluation of Comprehensive Community Initiatives. New York: Aspen Institute.

Doble, J. and M. J. Hughes (1994) Challenging Disadvantage: Barnardo's Anti-Poverty Strategy. Barkingside: Barnardo's.

Gaffikin, F. and M. Morrissey (1994) Brownlow Community Trust: Evaluation Report. Brownlow: Brownlow Community Trust.

Rossi, P. H. and H. E. Freeman (1989) Evaluation: A Systematic Approach. Newbury Park, CA: Sage Publications.

Sadan, E. and A. Churchman (1997) 'Process-focused and Product-focused Community Planning: Two Variations of Empowering Professional Practice', Community Development Journal 32(1): 3-16.

Traynor, T., K. Smith and M. J. Hughes (1998) Still Challenging Disadvantage: First Report on the Evaluation of Barnardo's Anti-Poverty Strategy. Barkingside: Barnardo's.

Weiss, C. H. (1995) 'Nothing as Practical as Good Theory: Exploring Theory-Based Evaluation of Comprehensive Community Initiatives for Children and Families', in J. P. Connell, A. C. Kubisch, L. B. Schorr and C. H. Weiss (eds) New Approaches to Evaluating Community Initiatives: Concepts, Methods and Contexts, p. 66. Washington, DC: Aspen Institute.

MIKE HUGHES is a Principal Officer, Research and Development, with Barnardo's. He is responsible for assisting with evaluation activities in the North East of England and Scotland, and takes a lead within the organization in relation 
Hughes \& Traynor: Reconciling Process and Outcome to community development. Please address correspondence to: Orchard House, Fenwick Terrace, Jesmond, Newcastle-upon-Tyne NE2 2JQ. [email:

mikehughes@compuserve.com]

TISH TRAYNOR has worked for many years as a social worker, a community development worker and manager, and latterly as the evaluation manager of Barnardo's Anti-Poverty Strategy. 